\title{
Monitoring and Evaluating Agricultural Science and Technology Projects: Theories, Practices and Problems
}

\author{
Erik Millstone, Patrick Van Zwanenberg and Fiona Marshall
}

\begin{abstract}
Recently there has been a realisation that agriculture, and in particular the viability and sustainability of smallholder farming, can be a key to poverty reduction in developing countries. This article reviews approaches to monitoring and evaluation (M\&E) of scientific and technological innovation projects and examines how approaches to $M \& E$ can be modified or enhanced to optimise positive impacts on those intended recipients. This article concludes that innovations are most successful when they are accomplished within 'innovation systems'; that advantage should be taken of opportunities to involve intended recipients of the innovation at early up-stream and mid-stream stages of projects to assess the accuracy and adequacy of theories of change; that the types of tools and methods used in carrying out M\&E influence the types of data obtained; and that the cultures of research and development institutions may inhibit reciprocal communications but the development of intermediaries between institutions and farmers could make a useful difference.
\end{abstract}

\footnotetext{
1 Introduction

The importance of agriculture for poverty reduction in developing countries has recently been more widely recognised than had been the case for several decades (All Parliamentary Group on Agriculture and Food for Development 2010). That was evident from the centrality of concerns about hunger, food and farming in the Millennium Development Goals, and has been reinforced by the diminishing prospect of reaching those goals. From the mid-1970s until the early years of the twenty-first century, smallholder agriculture was sometimes portrayed as old-fashioned and anti-modern (Alston et al. 2000). Recently however, there has been a growing realisation that improving the viability and sustainability of smallholder farming can be a key to poverty reduction amongst a very large proportion of poor people in developing countries (World Bank 2007). The central question in this discussion is: how far do current approaches to monitoring and evaluating scientific and technological innovation projects, as embodied in published guidelines and actual practices, provide opportunities to critically examine underlying assumptions about how the

innovation will benefit the intended recipients, particularly in smallholder agriculture?

Detailed and reliable statistics on the socioeconomic impact of agricultural research and development $(\mathrm{R} \& \mathrm{D})$ projects are not as plentiful as scholars and policymakers might wish. Evidence is available from studies that have attempted to estimate the 'rates of return' to investments in agricultural R\&D, but those have almost entirely derived from studies in industrialised countries (Alston et al. 2000). Alston et al. (2000: xiii) for example reported in 2000 on a meta-analysis of the results from 292 studies that in aggregate reported some 1,886 estimates of rates of return. 'Excluding two extreme outlier observations ... the average rate of return was 100 per cent per year for research, 85 per cent for extension, 48 per cent for studies that estimated the returns to research and extension jointly, and 81 per cent for all the studies combined. However, these averages give an incomplete and in some important ways misleading picture' (2000: ix). In 2006 Pardey et al. published a study on agricultural R\&D in developing countries, but that made no reference to 'rates of return' (Pardey et al. 2006).
} 
A recent review highlighted the fact that a range of ways have been developed with which to estimate the impact of investments in agricultural R\&D (Piesse and Thirtle 2010). In aggregate, returns to investments in agricultural R\&D may have been impressive especially in industrialised agriculture, but their contribution to reducing poverty amongst the poorest smallholder farmers in developing countries has had a less impressive track record. Neither of those two overviews provided data reporting outcomes project by project; their analyses aggregate returns on investments, but did not address distributional issues, as between different sets of beneficiaries. The evidence suggests that while some of the adopters of the innovations may have been relatively poor by comparison to farmers in the industrialised countries, they were often the more affluent farmers in the rural and peri-urban areas of developing countries. Poor smallholders and the landless rural poor were either unable to invest in many of the innovations, or lost out when the innovations were 'labour-displacing' rather than 'employment-generating'. The rates and patterns of adoption of novel technologies have been very variable and particularly low amongst the poorest of the poor, and the impacts of the adoption of those technologies on poverty alleviation have disappointed farmers, researchers and funders (Röling 2006a). Too often novel technologies have aggravated rather than diminished inequalities, diminished rather than increased agricultural employment, and undermined rather than improved social and/or ecological sustainability (Griffin 1974).

It is therefore important to gain an understanding of the conditions under which the desirable impacts of agricultural innovations can be enhanced and adverse effects diminished. Researchers and sponsors have endeavoured to assess their achievements by adopting $\mathrm{M} \& \mathrm{E}$ systems. M\&E systems have not however, consistently demonstrated project successes, which suggest that there is scope for improving the tools of appraisal as a step towards enhancing beneficial impacts, and diminishing harmful ones (IEG 2009). In this context, the key task will be to examine how far, and in which ways, approaches to $\mathrm{M} \& \mathrm{E}$ can be modified or enhanced to optimise positive impacts. That question will be addressed by reviewing how $\mathrm{M} \& \mathrm{E}$ practices have evolved and how they are currently designed and deployed.

\section{Approach}

The approach adopted for this discussion focuses not just on theories and practices of M\&E, but also on the theories of change that underpin agricultural R\&D projects. That approach has been chosen because the assumption is made that the eventual impacts of agricultural technology innovations depend upon the plausibility, adequacy and accuracy of the underlying theory of change adopted by the innovators, and their financial sponsors. This discussion is also premised on the idea that forms of $\mathrm{M} \& \mathrm{E}$ that pay attention to opportunities to gather data with which to test underlying theories of change will be far more beneficial than those that don't.

Project proposals typically indicate the changes in the lives of the projects' intended beneficiaries, and some causal mechanism by which those changes would be brought about. Theories of change are important because projects based on realistic and robust theories are more likely to deliver their envisaged impacts than those with assumptions that are unrealistic, naive or false (cf. NONIE 2009, especially para 3 p.xii). The central question in this discussion is: how far do current guidelines and practices provide opportunities critically to examine such theories? And to what extent have successful projects provided intended beneficiaries with opportunities to assess those theories of change, and enrolled them in identifying the most likely pathways towards success for the project and the beneficiaries alike?

M\&E of agricultural development projects often gathers data on progress towards planned milestones and timelines, which were selected to outline the sequence of steps by which the project should unfold. Those plans are typically predicated on a set of assumptions that consider that the underlying theory of change is correct; and those assumptions are typically neither tested nor questioned by the project team or by their sponsors. The intended beneficiaries are sometimes reported to be sceptical and cautious, but their voices are rarely heard by researchers or their sponsors (Chambers et al. 1989; Scoones and Thompson 2009).

This discussion draws on two main sets of information; firstly informed and research-based debates about how innovations occur, particularly 
in developing country agriculture. The second examines guidelines for $\mathrm{M} \& \mathrm{E}$ of agricultural $\mathrm{R} \& \mathrm{D}$ projects from several influential organisations. The final concluding section outlines the implications for moving forwards.

\section{Understanding industrial innovation: from linear to systemic models}

Until the 1970s, public policies for science and technology in the industrialised countries were based almost entirely on linear models of innovation. The first was a linear 'science-push' model, which portrayed scientific research as the initiator of innovations (Bush 1945). An increase in scientific inputs would lead more-or-less directly and automatically to an increase in the number of innovations and technologies flowing out of the 'pipeline' further downstream; which in turn were assumed to produce improvements in social and economic welfare. The linear 'science-push' model was widely interpreted as implying that what happened between the provision of scientific research and the uptake of new technologies was largely automatic; there was little need to understand processes and contexts of technological change. Consequently project evaluations tended to focus on comparing inputs and outputs of the system, for example research expenditures and patents, without much attention to what occurred before, during or after the process (OECD 1997). The implications for $\mathrm{M} \& \mathrm{E}$ were that monitoring should focus on progress against predetermined milestones, as well as bottlenecks that inhibit the flow from inputs to outputs, and evaluation should compare outputs to inputs. This approach to $\mathrm{M} \& \mathrm{E}$ survives but has more recently been supplemented with more rigorous and meaningful approaches, although some endeavour to remain within a linear technologypush framework, examples of which are provided below.

During the 1970s a second type of linear 'demand-pull' emerged, which portrays changes in demand as driving innovation. In this model, changes in patterns of demand elicit technological innovations, which in turn can stimulate further scientific development. It is a reversal or inversion of the former science-push model. Empirical studies of patterns of innovation across diverse industrial sectors show that few actual innovation processes matched either one of the linear models (Freeman and
Soete 1997). In practice, a multiplicity of patterns emerged including diverse hybrids of science-push and demand-pull processes by which innovations occurred. Neither model could adequately capture the conditions for success and failure in innovation.

In the early 1980s fresh ideas emerged suggesting that while science-push models were right to emphasise the importance of scientific and technological research, they were mistaken in supposing that investment in research alone would be sufficient for innovation. ${ }^{1}$ Similarly market-pull frameworks were correct to draw attention to influences on patterns of innovation from the demand side, and particularly to see matching user requirements as vital for success, but they were mistaken when inferring that public support for basic research was unnecessary (Arnold and Bell 2001).

Since the mid-1970s, innovation systems and models have become influential in academic and policy circles. The unit of analysis in systems approaches shifted from individuals and individual organisations to groups of organisations in innovation networks (Rosenberg 1971; Nelson and Winter 1982; Freeman and Foray 1993; Heilbroner and Thurow 1994; Dosi and Soete 1988; Hall et al. 2003). These groups were made up of multiple stakeholders including for example universities, research institutes, private sector firms along the input and output supply chains and their customers. These models highlighted the interactions amongst those groups and their potential for collective and interactive learning.

\section{Linear models of agricultural development}

Within the agricultural sector, there has been a recent but similar shift in understanding how agricultural technology innovation processes work, although that shift occurred far slower than in industrial sectors, especially in developing country agricultural systems. The traditional model of publicly funded agricultural research institutions, with results passed to the farmer by means of a network of extension agencies, had long assumed linear 'science-push' models of innovation (Eponou 1993).

While the agricultural research systems of developing countries have frequently pursued linear technology-push models, this has not been 
the case in countries like the USA, the UK and the Netherlands (Eponou 1993; Holmes 1988). In those countries, relatively well-functioning extension services not only provided farmers with access to new technologies and information, they also gathered problems and solutions from farmers and delivered this information to the 'up-stream' researchers. Reciprocal flows of knowledge were evidently beneficial; sustaining this feedback loop allowed all parties to be informed about each other.

Science-push linear models have dominated agricultural innovation policy in developing countries even today, in part because researchers and funding bodies often adopt very linear and compartmentalised views of innovation process (Röling 2006b). The compartmentalised way of thinking has the curious advantage that it can readily be combined with that Hood and Rothstein have characterised as 'blame avoidance' (Hood et al. 2001). Practitioners within individual compartments can readily ascribe blame for failures of the chain to be fully linked together to those in the other compartments. M\&E practices in these linear models typically focused on comparing inputs and outputs of the system. Mid-stream they may judge progress against pre-established milestones; downstream they may judge outputs and impacts, but underlying theories of change are rarely tested, especially not at an early stage in the development of technologies.

Clark has explained why linear models were adopted by the global agricultural research institutions operating under the auspices of the Consultative Group on International Agricultural Research (CGIAR or CG for short) and by many National Agricultural Research institutions (or NARs), and this helps explain why those organisations have struggled to address the needs of poor rural households (Clark 2002). Within the CG system there are no readily available means for farmers' problems to be communicated directly to researchers, who often act in accordance with traditional academic values, and with assumptions about the beneficial impacts of technological changes that are untested by the researchers, though perhaps doubted by the farmers and maybe others too. NARs also struggle to establish organisational interdisciplinary structures to focus on the problems faced by farmers. Research agendas are often set and technological trajectories pursued by reference to the scientific and technological aspirations of the researchers (and donors) rather than the needs of the intended beneficiaries. Various approaches have been developed that recognise that farmers have valuable knowledge of the characteristics and dynamics of the farmers' own ecological and socioeconomic environments. Those novel approaches were motivated by a perception that farmers could have foreseen or did foresee the problems that were outside the researchers' frame of reference. Participatory approaches to technology development were developed, encouraging scientists to communicate and collaborate with small-scale farmers in the design and execution of field experiments to develop technologies wanted by, and appropriate to, the conditions of those farmers.

In practice, however, those approaches have had a limited impact on agricultural technology innovation. Röling has argued that:

[National and international agricultural research centres] continue to believe in magic bullets and green revolution approaches for Africa. When the chips are down, core business for agricultural research remains breeding, biotechnology, smart farming, robotics and high input agriculture, and productivity per hectare. Marketing approaches, farming systems research, and participatory research so far have had only limited impact on the dominant policy model of technology transfer. ... Improving the impact of research is not so much a question of investing more in research, but in developing the ability of farmers to influence research. [emphasis added] (Röling 2006b)

Those impacts have been limited not just because of the researchers continue to accept linear models, but also partly because of institutional structures and routines. Farmers' understandings of the challenges facing them, and the relevance of technological innovations to their needs, have often been highly variable and context-specific, while institutionally the agricultural scientists are expected to generate solutions that can readily be scaled-up and scaled-out, across a wide range of different cultural and agro-ecological contexts. Röling's argument, which has been shared and endorsed by others, implies however that M\&E systems 
should include checks on whether farmers' voices were heard, and the mechanism through which the farmers' agendas influenced the design and selection of research projects.

\section{Applying an innovation system perspective to smallholder agriculture in developing countries} At the end of the 1990s, an innovation system perspective drawn from the manufacturing sector in industrialised countries began to be applied to agricultural innovation in developing countries. One important difference was that the 'demand' side of innovation systems has often been very weakly articulated, especially on the part of smallholders, who are typically numerous, individually weak and poorly represented (Barnett 2006). This implies that there may be a useful role for intermediaries who are able to understand both languages and cultures, and translate and broker between them; though that remark might be misunderstood as if it were selfinterested special-pleading (Howells 2006).

Barnett has argued that the key insight from the innovation system approach is to broaden narrow focus on 'research' to a wider concern with 'processes of innovation' (Barnett 2006). Barnett portrays much current practice as trying to funnel knowledge down a hosepipe, in the hope that at least some of it will emerge usefully at the other end. He argues that far more attention needs to be paid to where the knowledge needs to emerge and to investing in the processes, mechanisms and institutions that will utilise the knowledge once it emerges from the end of the pipe. Researchers and funders should consequently '...concentrate as much on the users of knowledge as they currently do on the suppliers of new knowledge...' (Barnett 2006) to enhance the poverty-reducing impacts of their endeavours.

If farmers and other users of research are to be more closely integrated into research processes than has often been the case, then monitoring and evaluation practices would need to be conducted in closer proximity to the intended beneficiaries of the research system. The reasons why that has been occurring insufficiently frequently have had to do with some researchers not appreciating the potential benefits, and others appreciating the benefits but lacking confidence in systematic ways of gathering and utilising their possible inputs.

\section{Guidelines and practices for M\&E of} agricultural research

$\mathrm{M} \& \mathrm{E}$ activities (not just in agriculture, but more generally too) have traditionally been used primarily for auditing and accounting purposes. However, M\&E could be used to improve performance by enriching the planning and implementation phases, and to improve future planning if lessons are learned from subsequent evaluations (IEG 2009). In this section, an evolving range of approaches is reviewed. In several cases, particular approaches are attributed to particular funding agencies, not to imply that they invented them or monopolise their use, but rather that they have chosen to endorse those approaches.

\subsection{How have M\&E theories and practices evolved and why?}

This section consists of a review of English-language documents that explicitly address issues of $\mathrm{M} \& \mathrm{E}$, both general documents and those particularly focused on agriculture, from organisations which have published those documents this century. The list was assembled using internet search tools. They include several organisations that are 'big players' and which consequently have been influential. The selection criteria included a requirement that they should provide comments on or advice on how, in practice, impact assessments can most effectively be incorporated into systems of monitoring and evaluation. Consequently, documents such as the World Bank's 2009 report from its Independent Evaluation Group and the 2009 report on Impact Evaluations and Development from NONIE (Network of Networks for Impact Evaluation) are not discussed in detail because they do not recommend specific procedures but rather focus on the conditions under which impact evaluations can be institutionalised, and incorporated into institutional policy reviews (IEG 2009; NONIE 2009).

\subsubsection{Logframes}

The traditional tool used for $\mathrm{M} \& \mathrm{E}$ within projects is the 'logframe' or logical framework. Logframes were initially developed as a planning tool for the US military, but were later adopted by USAID for development projects. By the late 1990s they had become the standard required by leading donor organisations (Bakewell and Garbutt 2005). Logframes require the specification of the objectives of any project or programme and the identification of the expected causal links in a linear chain running, usually in four stages, from 
inputs and activities, to outputs, then outcomes, and finally impacts. Inputs and activities refer to project resources and project activities; outputs are often understood as the direct products of agriculture research projects, for example new germplasm. Outputs are intended to achieve some direct effects, or outcomes, as a result of say, the uptake of new technologies, or other changes in agricultural practice. Finally, outputs and outcomes may have an impact, in terms of broader, longer term economic, social or environmental change (Pasteur and Turral 2006). Performance indicators may be selected at each stage. This framework can provide a basis for monitoring and evaluation of a project's progress (Pasteur and Turral 2006). This approach encourages people to be explicit up-stream about key aspects of their theories of change and about what they are trying to achieve and how. By specifying indicators it can indicate some selected changes for monitoring.

A recurrent criticism of logframe approaches has been that the focus on inputs, activities, outputs and outcomes fails to capture the complexity of the intervening processes or contributions from other essential stakeholders apart from the initial researchers such as technology users and intermediaries who adapt to threats and opportunities. The impact of agricultural innovations can also depend on other factors such as credit systems, markets for inputs and outputs, as well as supportive policies and institutions. The logframe approach also effectively assumes that researchers have adequate foresight, so neither unforeseen pathways nor unintended effects need be considered (Springer-Heinze et al. 2003; Bakewell and Garbutt 2005). Critics have argued that the logframe approach encourages managers to focus on work that can show reasonably predictable outcomes in relatively short time frames, and consequently may lose sight of emerging opportunities and unintended outcomes/impacts (Bakewell and Garbutt 2005). As the European Initiative for Agricultural Research for Development puts it:

Any model that assumes a single and uninterrupted causative line between research and development is likely to be unrealistic. Research usually impacts on the livelihoods of poor people through highly complex, dynamic and interactive processes involving many different factors and actors in addition to agricultural research. Politics, cultural traits, social conditions, economic interests and the requirements of the surrounding technology are all being amalgamated into some development change. ${ }^{2}$

That does not imply that $\mathrm{M} \& \mathrm{E}$ is a waste of time, but that there is more to $\mathrm{M} \& \mathrm{E}$ than traditional logframes can address. If intra- and inter-project learning is to be facilitated, it is important to establish not just what did and did not happen, but also why particular outcomes did or did not eventuate (Watts et al. 2008).

There has recently been increasing interest in how $\mathrm{M} \& \mathrm{E}$ project and programme evaluations might extend beyond traditional mid-stream monitoring and economic assessments, and contribute more to enhanced beneficial impacts and institutional learning. Extending the focus downstream, Springer-Heinze et al. proposed an 'impact orientation', which is a normative concept used to characterise organisations that achieve intended impacts, rather than just producing intermediate outputs, and which have robust theories of change (Springer-Heinze et al. 2003). This section outlines several ideas for M\&E, which take on board insights from innovation systems and are aimed at achieving intended impacts and enabling intra- and inter-project learning.

\subsubsection{Impact Pathway Analysis}

Impact Pathway Analysis (IPA) is an approach that includes a standard sequence of logframes, but the focus expands to include mapping, monitoring and gaining understanding of the process of moving from one stage to another; in particular, the shift from outputs to outcomes (Mackay et al. 2009).

To understand how the four stages from research activities to impacts are linked, users should specify the theories of changes within and between the stages (Mackay et al. 2009). For Douthwaite et al. the process of evaluating an impact pathway involves asking seven questions for each identified outcome, and recording these in a matrix:

1 What would success look like?

2 What are the factors that influence the achievement of each outcome?

3 Which of these can be influenced by the project? 
4 Which factors are outside the direct influence of the project?

5 What is the program currently doing to address these factors in order to bring about this outcome?

6 What performance information should we collect?

7 How can we gather this information? (Douthwaite et al. 2003)

Pathway analysis does not assume that the pathways that are followed in practice are either singular, simple or that the trajectories can be fully anticipated.

6.1.3 Participatory monitoring and evaluation (PM\&E) The focus of M\&E in the World Bank has shifted in recent years from monitoring implementation to tracking results (Rajalahti et al. 2005). The Bank indicated that both productivity and institutional impacts need to be assessed; the latter are required to enable the former, especially on a continued basis. The Bank advocated use of a simplified version of the logframe that emphasises indicating the steps from outputs to outcomes by specifying and then monitoring some of the intermediary links (Rajalahti et al. 2005). The Bank also recommended that partners and target communities should be involved in their selecting indicators. More generally, it discusses what it calls 'participatory monitoring and evaluation', which requires the active involvement of key stakeholders in the M\&E process to reach agreement about what will be monitored and evaluated, as well as how and when data will be collected and analysed, what the data actually mean, how findings will be shared, and what action should be taken. The Bank argues that participatory monitoring and evaluation is critical to ensuring that agricultural research projects and programmes are responsive to the genuine needs of intended clients, and to establishing what the actual (intended and unintended) impacts of a project are from the perspectives of stakeholders and intended beneficiaries (Rajalahti et al. 2005).

\subsubsection{EIARD's enhanced partial farmer participation}

The European Initiative for Agricultural

Research for Development (EIARD) is a group of leading European donors. It has a Task Force on Impact Assessment and Evaluation, which in
2003 published Impact Assessment and Evaluation in Agricultural Research for Development, which was intended to '...inspire readers to design and conduct impact assessments and evaluations that contribute more to the livelihoods of the poor and to learning. ${ }^{93}$ The approach was implicitly critical of conventional approaches. The task force argued that:

...impact assessments and evaluations should not be limited to directly measurable impacts; they should seek to capture the complexity and non-linear nature of agricultural innovation and sustainable development. Impact assessments and evaluations should also be integrated as far as possible into research programmes, to facilitate internal learning processes and changes that enhance the probability of impact. ${ }^{4}$

While the EIARD proposal represented an advance of the status quo ante, it did not address more up-stream opportunities for learning.

\subsubsection{CG's participatory impact pathway analysis (PIPA)}

The CG institutions provide guidance on a wide range of $\mathrm{M} \& \mathrm{E}$ techniques; here we focus on their guidance for one such technique, namely participatory impact pathway analysis (PIPA), which is chosen because it is directly relevant to the main narrative of this discussion, and because it represents a promising development. The difference between this approach, and the 'impact pathway assessment' described earlier, is that it is explicitly participatory and it involves the creation of network maps of relevant actors (a step that requires participatory approach), and aspires to successfully scaling-up and scaling-out of project interventions. PIPA attempts to capture underlying theories about how a project intervention is meant to change the status quo, using a range of participative techniques (Mackay et al. 2009).

The PIPA approach uses 'Network maps ... [as] ... a valuable tool in first identifying players who are key to the success of projects and then in helping the project monitor and evaluate its progress in forming and strengthening the research, scaling-out and scaling-up needed to achieve impact. Developed ex ante, network maps add critical and complementary information about the partners and the roles they must play for projected impacts to be achieved. [They...] 
help strengthen project theory by making explicit critical partner roles, relationship building and development, uncertainty, non linearity, and opportunity that are present in virtually all agricultural R\&D contexts' (Mackay et al. 2009). The implication is that those projects would also be more effective.

PIPA involves a workshop held at or near to the start of a project, which provides an opportunity for appraisal of theories of change at an early stage of the project and by the intended beneficiaries. The workshop should help participants make explicit, discuss and describe their hypotheses for how project activities and outputs could eventually contribute to desired goals such as poverty reduction. The description of these hypotheses is a description of the project's impact pathways. In practice, the PIPA proposal is rather optimistic, as smallholder farmers rarely have three days to spare and researchers who have the resources for such events have typically raised those funds by previously specifying how their efforts will bring about change; they are rarely given funds critically to appraise their theories of change.

According to CG personnel: 'Our experience is that when people are not constrained, at the outset, to fill in logframe boxes, they have tremendous energy for exploring collective ideas about how a project should work, or has worked. Therefore, in the PIPA workshop, participants only attempt to create a logic model once the underlying impact pathways have been discussed and agreed. ${ }^{5}$ (emphasis added). In other words, on the basis of their experience, they reported that there is considerable scope for up-stream participatory deliberation to critically appraise what, in this context, are referred to as underlying theories of change.

Researchers at IFPRI have also explored the use of network mapping of innovation system actors. The intention there was not to design $\mathrm{M} \& \mathrm{E}$ strategies but to examine the properties and performance of agricultural innovation systems (Spielman and Kelemework 2009). Nevertheless, it resembles a PIPA and so may be relevant to the kind of network maps discussed above. Participants in a workshop comprising members of a farmers' cooperative together with public sector researchers, were asked firstly to list all the actors they believed to be important to promoting or facilitating farmer innovation in the poultry sector. Secondly, they were asked to identify the important linkages amongst the different actors (categorised according to flow of production inputs, knowledge and information, credit and financial services, regulatory oversight, and coordination and cooperation). Thirdly, they were asked to evaluate the level of influence of each actor in promoting or facilitating farmer innovation, fourthly to rate whether that influence was positive or negative, and fifthly to reflect on the information and comment on the constraints, challenges and opportunities in the poultry sector (Spielman and Kelemework 2009: Appendix E). Such exercises might be useful when designing project interventions and to design $\mathrm{M} \& \mathrm{E}$ systems, and provide an indication that some protagonists within the CG system do appreciate the benefit of incorporating the farmers' understandings into their project design and planning.

\subsubsection{IFAD's 2002 Guidelines - an emphasis on up-stream appraisal of theories of change}

The focus of the International Fund for Agricultural Development's (or IFAD's) guidelines is predominantly a results-orientated, learning approach to $\mathrm{M} \& \mathrm{E}$, but to recognise the possibility for, and benefits of, up-stream appraisal of underlying theories of change, without using that terminology (IFAD 2002).

IFAD emphasises up-stream participation by intended beneficiaries and other stakeholders in project design (IFAD 2002). At an early upstream stage, when projects are being designed, opportunities are provided for intended beneficiaries and their local representatives, and other participants in systems of innovation to contribute to assessing the problems, with which they have to contend, analyse and assess options, and select indicators to be monitored.

\subsubsection{Gates Foundation Guidelines}

The Bill \& Melinda Gates Foundation's (BMGF) Guidelines to Applicants and the Template for a

Timeline and Milestones stipulate requirements for $\mathrm{M} \& \mathrm{E}$, using Milestones for each of the project's objectives and activities. The guidance does not explicitly refer to what is referred to here as a 'theory of change', but implicitly indicates the desirability of checking up-stream the plausibility and adequacy of projects' theories of change with representatives of the intended or 
Box 1 Multi-criteria mapping: an innovative methodology for up-stream learning

The multi-criteria mapping (MCM) methodology comprises four main steps.

The first involves developing a set of 'options', or in the case of the STEPS maize project, a set of nine 'innovation pathways'. An initial visit to, and round of interviews with, representative samples of farmers enabled a typology of nine alternative innovation pathways to be identified, all of which were potentially relevant to a population of subsistence farming households in a 'low potential' semi-arid region of Eastern Kenya, in the Sakai valley.

The second stage used a MCM methodology in a developing country for the first time. A sample of intended beneficiaries were interviewed, and introduced to the typology of pathways and asked to evaluate all of them against a set of criteria of their own choosing. Unlike most appraisal tools, this method does not guide or canalise the interviewees' selection of criteria. They were at liberty to focus on whichever considerations they deemed important, subject only to the condition that every criterion could be used to appraise each of the pathways. The central feature of this stage consists of a process by which each interviewee selects the criteria by reference to which they wish to appraise the options. The only constraints are that the criteria should be applicable to each of the options and to be independent of each other.

At the third stage the interviewees were asked to score each pathway, one at a time, using each of their criteria. Since such appraisals are often qualified with 'it all depends', interviewees were invited not just to give a single score on an ordinal scale, they were invited to provide both optimistic and pessimistic scores for each pathways under every criterion, and to give their reasons for their scores.

At the final stage of the interviews, participants were asked to weight their criteria in relation to each other, indicating their relative importance, which enabled the software through which MCM interviews are conducted to calculate overall 'ranks' for all of the pathways, using a linear additive weighting procedure; the ranks simply representing the weighted sum of the normalised scores.

The resulting data, which are both quantitative and qualitative, were then analysed both comparatively and in aggregation, from which emerged an evident consensus about the relative preferences amongst those farmers for particular developmental pathways rather than others. The output of that process included rankings of pathways that could inform members of the research community, and research funders about how resources could best be allocated, and how beneficial impacts for intended beneficiaries could be enhanced.

'target' beneficiaries. Proposers should indicate: 'Who are the target beneficiaries of your work and how does your approach specifically serve their documented needs?' and 'How have you consulted with your target beneficiaries and assessed their needs?' ${ }^{96}$ Those stipulations represent a clear indication that, before a research proposal is submitted, explicit steps should already have been taken to identify the perceptions and judgments of (representatives of) the intended beneficiaries. The requirement reliably to document the key problems faced by the 'target beneficiaries' represents a clear indication that the BMGF expects steps to have been taken to test theories of change by consulting the groups being targeted. The guidelines invite explicit articulations of a theory of change. If the proposers can make their theories of change explicit and comprehensible to the Foundation, they should also have accomplished the same result with those groups whose problems the researchers aim to solve. It remains to be determined whether, or how widely, that guidance has been followed. 


\begin{tabular}{|c|c|c|c|c|c|c|}
\hline \multirow{2}{*}{$\begin{array}{l}\text { Approach or } \\
\text { institution }\end{array}$} & \multirow[t]{2}{*}{ Year(s) } & \multicolumn{2}{|c|}{ Assumptions } & \multicolumn{3}{|c|}{ Monitoring and evaluation activities } \\
\hline & & Linear? & Uni-directional? & Downstream & Mid-stream & Up-stream \\
\hline Logframes & $\begin{array}{l}\text { 1980s and } \\
1990 s\end{array}$ & $\sqrt{ }$ & $\sqrt{ }$ & $x$ & $\sqrt{ }$ & $x$ \\
\hline IPA & 2009 & $x$ & $x$ & $\sqrt{ }$ & $\sqrt{ }$ & $x$ \\
\hline IFAD & 2002 & $\mathrm{n} / \mathrm{a}$ & $\mathrm{n} / \mathrm{a}$ & $\sqrt{ }$ & $\sqrt{ }$ & $\sqrt{ }$ \\
\hline EIARD & 2003 & $x$ & $x$ & $\sqrt{ }$ & $\sqrt{ }$ & $x$ \\
\hline $\begin{array}{l}\text { World Bank } \\
\text { PM\&E }\end{array}$ & 2005 & $\sqrt{ }$ & $\sqrt{ }$ & $\sqrt{ }$ & $\sqrt{ }$ & $x$ \\
\hline CGIAR PIPA & 2007 & $x$ & $x$ & $\sqrt{ }$ & $\sqrt{ }$ & $\sqrt{ }$ \\
\hline Gates Foundation & $\geq 2008$ & $\sqrt{ }$ & $\sqrt{ }$ & $\sqrt{ }$ & $\sqrt{ }$ & $\sqrt{ }$ \\
\hline MCM & 2010 & $x$ & $x$ & $\sqrt{ }$ & $\sqrt{ }$ & $\sqrt{ }$ \\
\hline
\end{tabular}

Key: ? = yes, $x=$ no, n/a = not applicable

\subsubsection{Multi-Criteria Mapping: an innovative tool for farmer participation}

Agricultural researchers have often found it rather difficult to engage with subsistence farmers, even when they tried to ascertain the needs and concerns of the farmers, as the intended beneficiaries of their research and development projects. Researchers have indicated that different farmers often have differing opinions, and even individual farmers may invoke multiple considerations, between which trade-offs might need to be made. In those circumstances, optimising amongst multiple concerns of diverse individuals and groups can be especially difficult. A recently conducted study applied an innovative methodology to the task of consulting with the intended beneficiaries of agricultural research to identify how they envisaged benefiting from a range of alternative agricultural technological trajectories (Thompson et al. 2009). It was conducted under the auspices of the STEPS Centre (which addresses Social, Technological and Environmental Pathways to Sustainability $)^{7}$ as part of a project exploring how poor farmers in sub-Saharan Africa can respond to and cope with climate change. While the study was not conducted at an early stage of research impact planning, the methodological innovation would be suitable in such circumstances. It could be used as a 'feed-in' rather than as a 'feed-back'. The procedure and outputs of a Multi-Criteria Mapping exercise are set out in Box 1.
The conceptual and institutional approaches to key features of M\&E reviewed above can be summarised in the following matrix, which tabulates the range of institutional approaches, the years in which the key documents were published, whether or not they make linear and uni-directional assumptions, and the extent to which they envisage conducting M\&E activities downstream, mid-stream and up-stream, using the terminology previously defined.

\section{Implications}

The implications of this discussion can be organised into four paragraphs:

Firstly, innovations are most successful when they are understood as initiatives that are accomplished by multiple protagonists within particular 'innovation systems'. When there are attempts to introduce technologies in conditions where there is no 'effective consumer demand', public indifference or even resistance, then poor rates of adoption and/or retention have to be anticipated.

Secondly, innovation projects all presuppose some 'theory of change' that imply that the introduction of the innovation will improve the lives of the intended beneficiaries. While researchers have often embarked on their projects by taking their theories of change for granted, there is a strong case for actively 
inviting the likely participants in the innovation system to assess and comment on the theory of change at an early stage in the process.

Traditionally, monitoring and evaluation of R\&D and innovation projects took place

retrospectively (ex post). If advantage is taken of opportunities to assess the accuracy and adequacy of theories of change at an early upstream stage (ex ante) and subsequently midstream stage too, it should enable innovative teams to recognise initial uncertainties and to respond subsequently to new information and to other learning opportunities.

Thirdly, there is a rich portfolio of tools and methods with which M\&E can be accomplished and enhanced. Different tools and methods lend themselves most readily to gathering information at differing stages of the process. Up-stream appraisals will inevitably be different from appraisals conducted once data on particular events and experiences within the project have become available. Differing tools entail gathering some types of data rather than others, and choosing from amongst different ways of analysing those data. The discussions

\section{Notes}

1 These new theories highlighted how innovation drew on and generated its own body of technology-specific knowledge. Stocks of technology-specific knowledge develop that influence the way firms identify the most fruitful (i.e. profitable) ways forward at the technological frontier. As a consequence, neither changes in market demand (marketpull) nor changes in science (science-push) influence innovation patterns directly. The effects of both are mediated by firms themselves and the particular bodies of knowledge they have accumulated.

\section{References}

All Party Parliamentary Group on Agriculture and Food for Development, Why No Thought for Food?, A UK Parliamentary Inquiry into Global Food Security, January 2010, www.agricultureandfoodfordevelopment.org/ Why\%20No\%20Food\%20for\%20Thought\%20\%20A\%20Parliamentary\%20Inquiry.pdf (accessed 20 July 2010)

Alston, J.M; Chan-Kang, C.; Marra, M.C.; Pardey, P.G. and Wyatt, T.J. (2000) A Metaanalysis of Rates of Return to Agricultural R\&D, above have highlighted some of the alternatives, and indicated how and why some are more appropriate and powerful than others.

Finally, there are many agencies or institutions within which those three conclusions have been recognised and accepted. That does not, however, entail that the practices implied in those three points are being operationalised; implementation has been more sporadic than systemic. This has partly been because of rigidities in the cultures of research and development institutions (amongst both practitioners and funding agencies). In some cases the incentives to operationalise the approach advocated above are weak, while in others enthusiasm for considering farmer participation is tempered by a lack of tools for implementation. Since some researchers have difficulties communicating with poor farmers, and poor farmers may have reciprocal difficulties, the development of experience and expertise amongst groups that know how to act as intermediaries between those two worlds may constitute an exciting advance.

2 www.eiard.org/docu/Eiard_Ia_paper.html (accessed 3 September 2010).

3 www.eiard.org/docu/Eiard_Ia_paper.html (accessed 3 September 2010).

4 www.eiard.org/docu/Eiard_Ia_paper.html (accessed 3 September 2010).

5 http://boru.pbworks.com/Online-manual (accessed 3 September 2010).

6 See www.gatesfoundation.org/grantseeker/ Documents/Guideline_AG_Proposal.doc (accessed 3 September 2010).

7 See www.steps-centre.org/ (accessed 3 September 2010).

IFPRI Research Report 113, www.ifpri.org/publication/meta-analysis-ratesreturn-agricultural-r-d (accessed 2 August 2010: 5)

Arnold, E. and Bell, M. (2001) 'Some new ideas about research for development', in Danish Ministry of Foreign Affairs, Partnership at the Leading Edge: a Danish Vision for Knowledge, Research and Development, April, www.um.dk/ NR/rdonlyres/7CD8C2BC-9E5B-4920-929CD7AA978FEEB7/0/CMI_New_Ideas_R_for_ D.pdf (accessed 3 September 2010 ) 
Bakewell, O. and Garbutt, A. (2005) The Use and Abuse of the Logical Framework Approach, Stockholm: Swedish International Development Cooperation Agency (Sida)

Barnett, Andrew (2006) Journeying from Research to Innovation: Lessons from the Department for International Development's Crop Post-Harvest Research Programme 'Partnerships for Innovation' Final Report, www.thepolicypractice.com/ papers/1.pdf (accessed 4 September 2010)

Bush, V. (1945) Science: The Endless Frontier, Washington DC, www.nsf.gov/od/lpa/nsf50/ vbush 1945.htm (accessed 3 September 2010)

Chambers, R.; Pacey, A. and Thrupp, L-A. (eds) (1989) Farmer First, London: Intermediate Technology Publications

Clark, N. (2002) 'Innovation Systems, Institutional Change and the New Knowledge Market: Implications for Third World Agricultural Development', Economics of Innovation and New Technology 11.4-5: 353-68

Dosi, G. and Soete, L. (1988) 'Technical Change and International Trade', in G. Dosi, C. Freeman, R. Nelson and L. Soete, Technical Change and Economic Theory, London: Pinter Press: 401-31

Douthwaite, B.; Kuby, T.; van de Fliert, E. and Schulz, S. (2003) 'Impact Pathway Evaluation: An Approach for Achieving and Attributing Impact in Complex Systems', Agricultural Systems 78.2: 243-65

Eponou, T. (1993) Partners in Agricultural Technology, ISNAR Research Report 1, The Hague: International Service for National Agricultural Research (ISNAR)

Freeman, C. and Foray, D. (eds) (1993) Technology and the Wealth of Nations, London: Pinter

Freeman, C. and Soete, L. (1997) The Economics of Industrial Innovation (3rd edn), London: Pinter

Griffin, K. (1974) The Political Economy of Agrarian Change: An Essay on the Green Revolution, Cambridge, MA: Harvard University Press

Hall, A.; Sulaiman, R.; Clark, N. and Yoganand, B. (2003) 'From Measuring Impact to Learning Institutional Lessons: An Innovation Systems Perspective on Improving the Management of International Agricultural Research', Agricultural Systems 78: 213-41

Heilbroner, R. and Thurow, L. (1994) Economics Explained, New York: Simon and Schuster

Holmes, C.J. (1988) 'Science and the Farmer: The Development of the Agricultural Advisory Service in England and Wales, 1900-1939', Agricultural History Review 36.1: 77-86
Hood, G.; Rothstein, H. and Baldwin, R. (2001) The Government of Risk: Understanding Risk Regulation Regimes, Oxford: Oxford University Press

Howells, J. (2006) 'Intermediation and the Role of Intermediaries in Innovation', Research Policy 35: 715-28

IEG (2009) Institutionalizing Impact Evaluation within the Framework of a Monitoring and Evaluation System, Washington DC: World Bank Independent Evaluation Group (IEG), www.worldbank.org/ieg/ecd/docs/inst_ie_ framework_me.pdf (accessed 18 August 2010)

IFAD (2002) Managing for Impact in Rural Development: A Guide for Project MEEE, www.ifad.org/evaluation/guide/ (accessed 3 September 2010)

Mackay, R.; Douthwaite, B.; Alvarez, S.; Keatinge, J.; Thiele, G. and Watts, J. (2009) 'Participatory Impact Pathways Analysis and Priority Setting', in J. Scholberg, S. Doglotti, C. Leoni, C.M. Cherr, L. Zotarelli, and W. Rossing (eds) Priority Setting Compendium, Washington DC: Consultative Group on International Agricultural Research (CGIAR), http://cgiar2009.joomlates.net/content/ participatory-impact-pathways-analysis-andpriority-setting (accessed 3 September 2010)

Nelson, R. and Winter, S. (1982) An Evolutionary Theory of Economic Change, London: The Belknap Press of Harvard University

NONIE (2009) Impact Evaluations and Development, Network of Networks for Impact Evaluation, Washington DC: World Bank, www.worldbank.org/ieg/nonie/guidance.html (accessed 3 September 2010)

OECD (1997) National Innovation Systems, Paris, www.adiat.org/documento/33.pdf (accessed 3 September 2010)

Pardey, P.G.; Alston, J.M. and Piggott, R.R. (2006) Agricultural RED in the Developing World, Washington DC: International Food Policy Research Institute

Pasteur, K. and Turral, S. (2006) A Synthesis of Monitoring and Evaluation Experience in the Renewable Natural Resources Research Strategy $(R N R R S)$, London: Department for International Development (DFID)

Piesse, C. and Thirtle, C. (2010) 'Agricultural R\&D, Technology and Productivity', Phil. Trans Royal Society B 365: 3035-47, http://rstb.royalsocietypublishing.org/content/ 365/1554.toc (accessed 18 August 2010) Rajalahti, R.; Woelcke, J. and Pehu, E. (2005) 
Monitoring and Evaluation for World Bank Agricultural Research and Extension Projects: A Good Practice Note, Agriculture and Rural Development Discussion Paper 20, Washington DC: World Bank

Röling, N. (2006a) Conceptual and Methodological Developments in Innovation, http://webapp.ciat.cgiar.org/africa/pres.htm (accessed 2 August 2010)

Röling, N. (2006b) Conceptual and Methodological Developments in Innovation, www.innovationafrica.net/pdf/s12_keynote_ full.pdf (accessed 3 September 2010)

Rosenberg, N. (1971) The Economics of Technological Change, London: Penguin Books

Scoones, I. and Thompson, J. (eds) (2009) Farmer First Revisited; Innovation for Agricultural Research and Development, London: Practical Action

Spielman, D. and Kelemework, D. (2009) Measuring Agricultural Innovation System Properties and Performance: Illustrations from Ethiopia and Vietnam, IFPRI Discussion Paper 00851, Washington DC: International Food Policy Research Institute (IFPRI)
Springer-Heinze, A.; Hartwich, F.; Henderson, J.S.; Horton, D. and Minde, I. (2003) 'Impact Pathway Analysis: An Approach to Strengthening the Impact Orientation of Agricultural Research', Agricultural Systems 78: 267-85

Thompson, J.; Brooks, S.; Morgan, M.; Millstone, E.; Odame, H.; Karin, F. and Adwera, A. (2009) Environmental Change and Maize Innovation in Kenya: Exploring Pathways In and Out of Maize, STEPS Working Paper 36, www.steps-centre.org/publications/ index.html\# maizebr (accessed 4 September 2010)

Watts, J.; Horton, D.; Douthwaite, B.; La Rovere, R.; Thiele, G.; Prasad, S. and Staver, C. (2008) 'Transforming Impact Assessment: Beginning the Quiet Revolution of Institutional Learning and Change', Experimental Agriculture 44: 21-35

World Bank (2007) World Development Report 2008: Agriculture for Development, http://siteresources.worldbank.org/ INTWDR2008/Resources/WDR_00_book.pdf (accessed 21 January 2010) 